\title{
La cartografía como método de investigación en psicología
}

\section{Cartography as a method in psychology research}

\section{A cartografia como método de pesquisa em psicologia}

\author{
Javier Rey \\ ORCID ID: 0000-0002-3211-5174 \\ Universidad de la República, Uruguay \\ Andrés Granese \\ ORCID ID: 0000-0002-0461-4347 \\ Universidad de la República, Uruguay \\ Autor referente: javierrey1@gmail.com
}

Historia Editorial

Recibido: 07/08/2017

Aceptado: 20/06/2018

\section{RESUMEN}

El presente trabajo tiene el fin de generar un aporte metodológico a la investigación en psicología, desarrollando algunas características de la cartografía como método válido en investigación. En primera instancia se realiza una breve descripción de la cartografía como concepto a través de los aportes de Deleuze y Guattari en su trabajo sobre el rizoma. Asimismo se presentan algunos antecedentes de su utilización metodológica en antropología y psicología desde autores como Néstor Perlongher, Suely Rolnik, Félix Guattari y varios investigadores de la academia brasileña. En un segundo momento se desarrollan tres temas concernientes a la cartografía, que surgen de la

experiencia de los autores a partir de las investigaciones y los procesos de escritura de sus tesis de maestría en psicología: el trabajo sobre el acontecimiento en el transcurso de la investigación, la dispositivación como un concepto adecuado para este trabajo y el campo de fuerzas que diagrama el problema de la investigación. En la conclusión se problematiza la propuesta de la cartografía, más que como una opción metodológica, como un desborde epistémico inherente a la práctica e investigación en psicología, dando cuenta de las crisis en la delimitación sujeto-objeto, en la construcción de procesos discontinuos y en la tensión afecto-representación. 
Palabras clave: Cartografía; Investigación; Psicología

\section{ABSTRACT}

This paper pretends to make a methodological contribution to psychology research, developing some characteristics of cartography as a valid method in research. In a first instance, a brief conceptual description of cartography is performed through Deleuze and Guattari contributions in the field, taking into consideration their development of rhizome. Likewise, theoretical background is presented related to the methodological use in anthropology and psychology from authors such as Néstor Perlongher, Suely Rolnik, Félix Guattari and several researchers from brazilian academy. In a second instance, three topics concerning cartography are

approached, which emerge from the experience of the authors as part of the writing process of their psychology master degree thesis: the work about happening through the course of research, devicezation as a suitable concept for these works and the force field that diagrams the research problem. In the concluding section, the cartography proposal is problematized, more than a methodological option, as an epistemic overflow inherent to research practice in psychology, therefore giving account about subjectobject delimitation crisis, in the construction of discontinuous process and affection-representation tension.

Keywords: Cartography; Research; Psychology

\section{RESUMO}

Este trabalho procura gerar uma contribuição metodológica para pesquisa em psicologia, desenvolvendo algumas características da cartografia como método válido em pesquisa. Em primeira instância, uma breve descrição da cartografia como conceito é realizada através das contribuições de Deleuze e Guattari em seu trabalho sobre o rizoma. Alguns antecedentes de uso metodológico em antropologia e psicologia também são apresentados a partir de autores como Néstor Perlongher, Suely Rolnik, Félix Guattari e vários pesquisadores da Academia Brasileira. Em segunda instância desenvolvem-se três questões sobre a cartografia, decorrente da experiência dos autores da pesquisa e do processo da escrita das teses de mestrado em psicologia: trabalhar sob 0 acontecimento no curso da pesquisa, a dispositivação como um conceito apropriado para este trabalho e o campo de forças que diagrama o problema de pesquisa. $\mathrm{Na}$ conclusão, $\mathrm{O}$ cartografia proposta torna-se problemática, e não como uma opção metodológica, como um estouro epistêmica inerente à prática e pesquisa em psicologia, percebendo a crise na delimitação de sujeito e objeto, na construção de processos descontínuos e na tensão afectorepresentação.

Palavras chave: Cartografia; Pesquisa; Psicología 


\section{Introducción}

I presente artículo pretende ser un aporte metodológico para la investigación en
el área de las Ciencias Sociales, Humanas y de la Salud, fundamentalmente de la Psicología. Se apoya en las tesis de Maestría en Psicología Social de los autores. A partir de estas se presentan problemas metodológicos y una elaboración conceptual que se entiende novedosa en este campo.

El artículo se estructura en tres secciones: una presentación del concepto de cartografía en la obra de Deleuze y Guattari; una presentación de los principales antecedentes del mundo académico a través de los cuáles la cartografía se posiciona como un método válido y fundamental para cierto tipo de investigación; y, posteriormente, bajo el título Cartografía y a punto de partida de las Tesis de los autores, desarrollamos algunos problemas y conceptualizaciones de orden metodológico y epistemológico. Este apartado se organiza del siguiente modo:

- Sobre el acontecimiento trabajará esta noción y la pondrá como el objeto mismo de la investigación cartográfica siendo que entre ambos se plantea una relación de presuposición recíproca.

- Dispositivación trabaja un triángulo conceptual: superficie de registro, dispositivo y agenciamiento, siendo la dispositivación el movimiento de actualización de los tres anteriores y a través del cual se habilita lo cartográfico.

- El campo de fuerzas que fuerza a pensar problematiza las nociones de campo y trabajo de campo, usuales en la investigación social para, a través de la noción de borde, deshacer las fronteras estructuradas de toda investigación: trabajo de campo análisis - escritura.

Por último, la conclusión trabaja sobre la delimitación de un campo epistemológico propio de la psicología donde el acontecimiento se vuelve su búsqueda y su producción y la cartografía el método fundamental para trabajarlo. 


\section{Antecedentes}

El concepto de cartografía, como método para la investigación, tiene sus raíces en Mil mesetas (Deleuze y Guattari, 2006) como una de las características del rizoma. Un rizoma se define como una especie vegetal cuya forma difiere de la arborescente al no poderse distinguir en él las raíces de las ramas y tener un crecimiento indefinido e indiferenciado. La cartografía será el trazado del mapa del rizoma en cuestión: intuitivo en muchas de sus líneas, se orientará a través de una multiplicidad conectiva, cambiante, asignificante. No se trata de reinstalar dicotomías, tendrá sus zonas de repetición, de redundancias, sus fronteras.

Es un mapa inmanente que construirá el territorio en su mismo trazado, no lo preexiste ni se extiende más allá del dibujo cartográfico. Así mismo este mapa no es independiente del cartógrafo pues opera por ese punto de indiscernimiento que es la afección. El cartógrafo se envuelve en las fuerzas del territorio y las sigue. ¿Qué líneas seguir, hasta dónde continuarlas, cuándo se cortan? Estas son las preguntas para hacerse dentro de un rizoma y en la construcción de una cartografía. Pero que el mapa no pueda ser independiente del sujeto que lo traza no instala un subjetivismo. Pues no hay sujeto, en el sentido de que el sujeto en cuestión se torna una fuerza más del territorio, productora del mismo. Pero en tanto fuerza, porque un sujeto es también el punto de estabilización que permite señalarlo como tal.

La cartografía irá entonces tras las fuerzas que habitan ese territorio. Las cuáles nos son interiores al mismo. Todo rizoma está en conexión con un afuera que lo atraviesa. La cartografía no se pregunta entonces por la esencia de algo (¿qué es?) sino por su funcionamiento (¿con qué conecta, con qué hace máquina?).

Tras la descripción realizada por Deleuze y Guattari sobre el concepto de cartografía, se ha propiciado la disposición cartográfica como un método válido de investigación en diferentes ramas de las ciencias sociales. Félix Guattari propuso como método de 
investigación e intervención en psicología lo que denominó cartografías esquizoanalíticas. En este campo define cuatro dimensiones de composición del encuentro: territorios existenciales, phylums maquínicos, flujos signalécticos y universos incorporales. Universos incorporales es la dimensión que se abre y habilita a la cartografía a una producción impensable de nuevos territorios existenciales, modos maquínicos de funcionamiento y nuevas semióticas. Guattari desarrolla esta mirada en varios escritos y conferencias durante la década del '80 (Guattari, 1992, 2013) y publica, finalmente, un libro específico sobre el tema: Cartografías Esquizoanalíticas (Guattari, 1989).

Néstor Perlongher hace su aporte a la cartografía desde la antropología en sus investigaciones sobre la prostitución masculina. Donde, si bien denomina estas investigaciones como etnografías, tanto el marco teórico al que se refiere como el mismo posicionamiento en el campo, coloca estas investigaciones en el ámbito de la cartografía.

La tarea del cartógrafo deseante no consiste en captar para fijar, para anquilosar, para congelar aquello que explora, sino que se dispone a intensificar los propios flujos de vida en los que se envuelve, creando territorio a medida que se los recorre. El mapa resultante, lejos de restringirse a las dimensiones físicas, geográficas, espaciales, ha de ser un mapa de los efectos de superficie (no siendo la profundidad, con Foucault, más que un pliegue y una arruga de la superficie). (Perlongher, 1996, p. 65)

Perlongher, en la misma línea de Guattari, presenta la cartografía como una intensificación de los flujos de vida y no como una simple investigación externa a los acontecimientos. Con el mismo fin de intensificar líneas de vida encontramos a Suely Rolnik, quién también impulsa un método cartográfico en psicología. La importancia del campo social investigado o del objeto de investigación no radica en él mismo, sino por el entramado intenso que compone con la cartografía. El cartógrafo investiga las 
formaciones deseantes y los supuestos objetos cobran importancia por la relación maquínica del territorio en estas formaciones deseantes.

A prática de um cartógrafo diz respeito, fundamentalmente, às estratégias das formações do desejo no campo social. E pouco importa que setores da vida social ele toma como objeto. O que importa é que ele esteja atento às estratégias do desejo em qualquer fenômeno da existência humana que se propõe perscrutar. (2006, p. 65)

En Cartografía Sentimental (2006) Rolnik describe algunas características de la cartografía respecto a un posicionamiento intenso, ético, estético y político en el campo de investigación.

Por último tenemos lo que seguramente es el antecedente más importante y sistematizado de la utilización de la cartografía como método de investigación: Pistas do Metodo da Cartografía (Passos, Kastrup y da Escóssia, 2009). Este libro está producido por un equipo de docentes de distintas universidades brasileñas (Universidad Federal de Fluminense, Universidad Federal de Rio de Janeiro, Universidad Federal de Sergipe), quienes señalan algunas pistas sobre el método. A partir de sus propias experiencias de investigación, articulan conceptos y problemas metodológicos para pensar la cartografía puesta en juego en la producción de conocimientos. Los autores ofrecen ocho pistas, aclarando que responden a problemas e invenciones propias de sus procesos de investigación y ninguna de ellas puede tomarse como Ley de cartografía, sino como ilustración de la búsqueda de problemas y la creatividad inherente a un proceso cartográfico y su cartógrafo.

Pistas do método da cartografía es un intento académico de actualizar el concepto de cartografía como un método de investigación, ideal para las Ciencias Humanas y Sociales. Sus pistas nos llevan por problemas, fundamentaciones e invenciones. Triada que quizá sea el mismo movimiento de cualquier cartografía. 


\section{Cartografiar}

A continuación, presentaremos problemas y aprendizajes cartográficos surgidos en nuestras investigaciones para la obtención del título de Magister en Psicología Social de la Facultad de Psicología (FP) de la Universidad de la República (UdelaR).

La tesis de Javier Rey El acontecimiento en las prácticas psicológicas (2015) trabaja una tensión inherente a esta disciplina: ¿En una práctica gubernamental (Foucault, 2006, 2007) cómo es posible la emergencia de un acontecimiento como algo novedoso, que no caiga en una redundancia, ni sea meramente normalizador? Estudia esta tensión en varios espacios: un grupo de investigadores estudiantes universitarios (a través del Programa de Apoyo a la Investigación Estudiantil, de la Comisión Sectorial de Investigación Científica) que realizaron un proceso cartográfico en un liceo sobre violencia de género; laboratorios del desnudo (de los cuales fue coordinador); el análisis de una consulta clínica con un paciente; el proyecto de extensión Clínica,Territorio y Entramado Social, de la Facultad de Psicología, UdelaR; y también tomó como parte de su trabajo de campo la propia escritura de la tesis. El método seguido para esta investigación de maestría fue cartográfico.

La tesis de Andrés Granese La invención en la práctica del Maestro Comunitario (2015) se trató de una etnografía realizada en una escuela del barrio Punta de Rieles (Montevideo) durante 9 meses. En ella se buscó comprender cómo dos Maestras Comunitarias crean su labor cotidianamente. Si bien fue una etnografía, el sentido orientador a través del proceso de investigación, fue definido como cartográfico. Los espacios analizados fueron el barrio, la escuela, la casa de los niños, distintos espacios colectivos (comedor, centro cultural, entre otros), la calle, la ANEP (Administración Nacional de Educación Pública), la "marcha de las túnicas blancas" (movilización sindical masiva en pedido de presupuesto para la educación). 


\section{Sobre el acontecimiento}

Un punto relevante en ambas tesis fue el trabajo sobre el acontecimiento (Deleuze, 1989, 2002), como concepto y como experiencia, como pregunta cartográfica, pues sólo a partir de esta disposición metodológica el acontecimiento puede emerger en su potencia inventiva. Relación necesaria entre cartografía y acontecimiento, éste traza las líneas del mapa: "Al final, la cartografía era el modo de seguir las líneas de un rizoma y nunca sabemos hacia dónde nos llevan esas líneas" (Rey, 2015, p. 106).

El acontecimiento nos espera, nos hace señas (Deleuze, 2002). Es impersonal y se escribe en infinitivo. El acontecimiento no es "yo corro" o "él corre". El acontecimiento es se corre, se come, se estudia, etc. El acontecimiento se encarna y por esto nadie puede decir con exactitud final qué es correr, comer, estudiar. Encarnar es singularizar, subjetivarse. "Inventamos el acontecimiento que nos inventa, dado que todo acontecimiento es singular y que no somos más que los acontecimientos que vivimos" (Granese, 2015, p. 228).

Encarnar un acontecimiento es actualizarlo (Deleuze, 2002). La tesis La invención de la práctica del Maestro Comunitario (MC) (Granese, 2015), pregunta qué es "lo comunitario" en términos de acontecimiento. No se limita a una definición terminológica, ni de política educativa, ni a una conceptualización académica. Ni siquiera a lo que las propias $\mathrm{MC}$ dicen al respecto. Todo esto sería, aunque muy válido, representaciones.

En otro lugar presentamos un análisis específico de "lo comunitario" como acontecimiento (Granese, 2016), ésta vez referimos al hecho de que la cartografía plantea las cosas en términos de acontecimiento. Se vuelve el método del acontecimiento.

Lo interesante es sentir qué llevó a cartografiar "lo comunitario", porque esto no fue planteado a priori. La etnografía realizada no se limitó a registrar sentidos y 
significaciones del colectivo con el que se investigó. Esto solo hubiera sido un acto de reconocimiento, reconocer lo ya conocido (por uno mismo o por los demás).

Todo acontecimiento es infinito en su virtualidad, entonces por qué es que se actualiza en tal y tal estado de cosas. "Lo comunitario" se manifestó como un cliché: se dice mucho, en muchos lugares, sobre muchas cosas y todos suponen entender lo mismo. Cuanto más cliché se vuelve un acontecimiento más muestra (aunque ocultándolo) su infinito virtual. La tesis investigó este acontecimiento. Pudo haber sido otra tesis, pues la invención en la práctica de los $M C$ es un rizoma que pliega a cartógrafo y acontecimiento en una de sus líneas posibles. Seguir esta línea es cartografiar, y solo se cartografía en términos de acontecimiento.

Un principio cartográfico es que no se mapean formas sino las fuerzas que producen ese estado de cosas. Un cliché es una forma estabilizada en las prácticas y los sentidos de un colectivo. Cuanto más rígida se presenta una forma, más debemos preguntarnos por las fuerzas que, invisibilizadas, han cristalizado de ese modo particular.

Cartografiar es tener un encuentro único con el acontecimiento, con un no saber sobre el mismo. Se cartografían los caminos de una ignorancia inaugural que nos convoca, abriendo una sensibilidad hacia ella. Hace borde con el cartógrafo. Abre un punto de afectación e indiscernimiento: habitar la ignorancia como una llamada al pensamiento, es la imposibilidad de objetivar $y$, por tanto, de subjetivarse uno mismo como distanciado del objeto. No se traza el mapa de un objeto ni de un sujeto, sino de un borde.

Cartografiar implica un doble movimiento de medio y borde: aquel porque uno ingresa en un campo de fuerzas ya dado y produciendo; el segundo porque ese borde es el afuera de ambos. Campo y cartógrafo están en una relación de presuposición recíproca. Campo no es ese borde, es infinitamente más, al igual que el cartógrafo, pero la cartografía es ese borde por primera y única vez para siempre. No es la 
representación de una realidad, es la construcción de un problema, el despliegue de una de las líneas del territorio.

Seguir una afectación implica un encuentro con el afuera (Blanchot, 2008; Deleuze, 2015), con lo impensable mismo del pensamiento. Es el encuentro con una fuerza fundamental que nos fuerza a pensar (Deleuze, 2009b).

La tesis La invención en la práctica del MC presenta un mapa de los elementos que componen la labor de las maestras comunitarias (Granese, 2015, pp. 107-110). Lo traemos para diferenciar, gráficamente, lo que entendemos por representar y lo que entendemos por cartografiar. A continuación presentamos aquel registro (figura 1): 


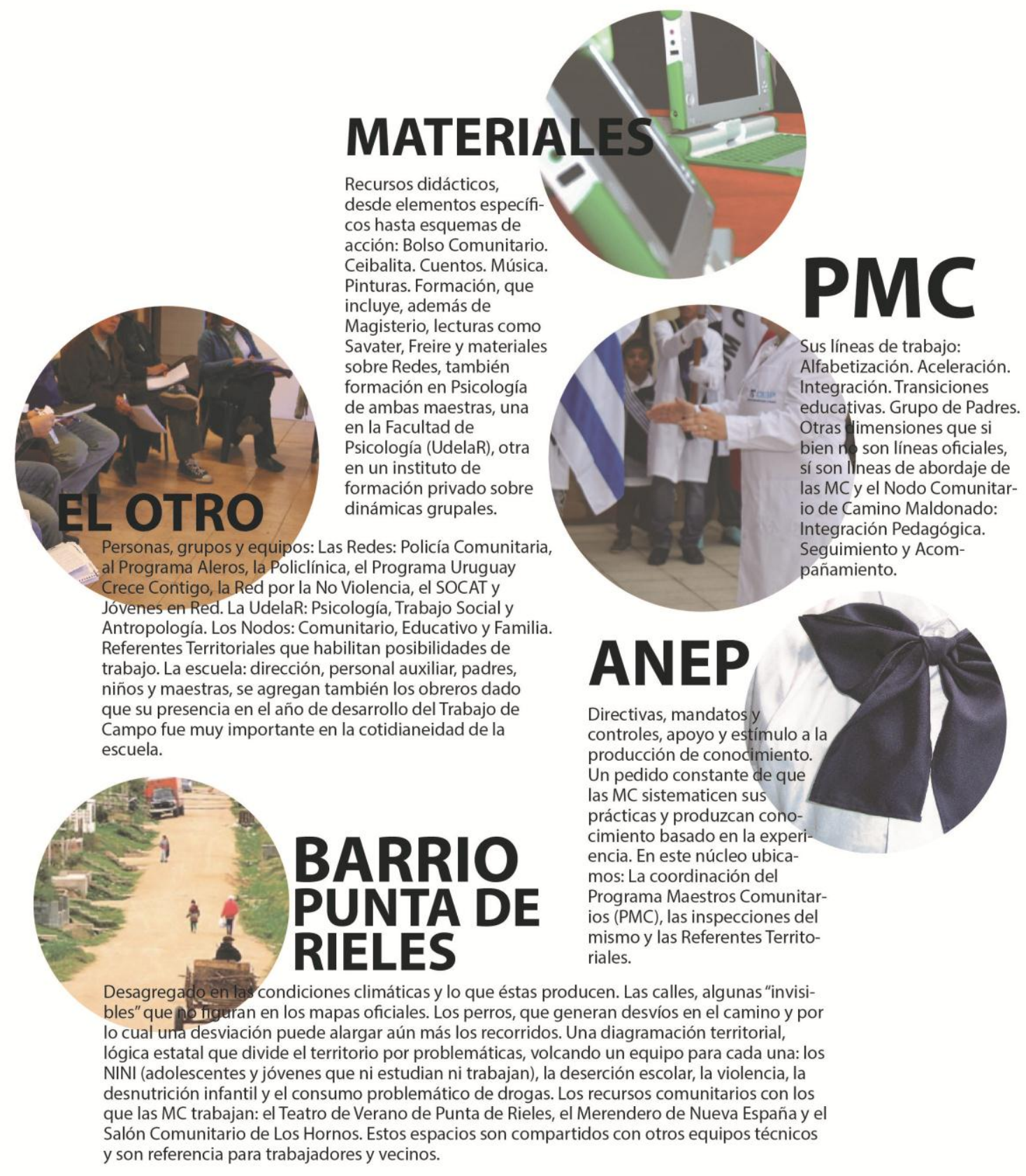

Figura 1. Mapa cartográfico de elementos que componen la tarea de los maestros comunitarios. (Granese, 2015)

La red total de conexiones es inabarcable, pero resulta interesante observar todos los elementos que se actualizan en las $M C$ ante cada acontecimiento. Estos son representaciones, se asemejan a cierta actividad de calco. Muchos inimaginables 
previos a la entrada al barrio: la importancia de los perros, de las distancias, del clima, etc. Ver estas cosas y las conexiones entre ellas es una investigación extensa, pero no necesariamente una cartografía, pues lo que se configura como cartografía es el mapeo, no solo de objetos, personas, reglamentos, etc., sino de las fuerzas que los actualiza y concatena de modo tal que se vuelvan importantes, definitorios, de la actividad de ambas maestras comunitarias.

Esa fuerza fue lo que se llamó el acontecimiento de "lo comunitario". La llave de esta puerta, aquello que plegó al cartógrafo cartografiando, no decantó de una linealidad entre lo visto, lo hablado y lo pensado. En este punto se pierde la posibilidad de representar, de calcar. Experimentar "lo comunitario" escondía elementos como la falta de vidrios y luz eléctrica en los espacios de trabajo, la necesidad de construir una labor educativa con un niño cuya vida cotidiana está pautada por la violencia, el robo, las armas de fuego. Todo eso también era "lo comunitario" y escapaba del cliché. En todo esto había algo que ya no era representable. Nos encontrábamos por fuera del reconocimiento: en la afectación.

Si tomamos como afectación ese punto donde no se puede distinguir sujeto y objeto, diremos que las $M C$ no son personas que trabajan en el PMC, ni que trabajan con niños de la comunidad. Ellos son el acontecimiento de "lo comunitario". Y el cartógrafo no es un observador, ni un analizador de un trabajo que se nomina coloquialmente “comunitario". Él es el acontecimiento de "lo comunitario".

La noción de acontecimiento cobra un estatuto especial aquí: no es solo algo novedoso, disruptivo, en el campo de estudio, es el campo de investigación en sí. Cartografiar no es registrar hechos como coleccionando acontecimientos, es tomar el campo como acontecimiento, lo que es igual a decir: tomar el acontecimiento como campo. Por esto mismo (ya lo veremos) el trabajo de campo no es una instancia distinta a la escritura de la tesis, pues escribir sobre el acontecimiento es trabajo de campo también. 
La investigación derivó hacia esa pregunta: ¿cómo es el acontecimiento de "lo comunitario"? y sobre todo ¿hacia dónde nos llevan sus derivas? Más allá de esta investigación concreta, toda cartografía comprende siempre una nueva deriva.

\section{La dispositivación en la cartografía}

Estas derivas necesitan una formación que permita el pasaje de la afectación pura del acontecimiento a la producción de un conocimiento procesual, que no tiene como fin un saber, sino como medio un aprendizaje. A este movimiento le llamamos dispositivación.

Tenemos tres elementos: superficie de registro, agenciamiento y dispositivo. Dibujémoslos como tres puntos en un plano. Devienen tres vértices de un triángulo, no podemos decir si equilátero; es decir, si los tres conceptos se posicionan entre sí de manera equilibrada. Surge un concepto de área, delimitado por estos tres puntos: dispositivación.

Para comprender cuál es para nosotros la necesidad de este nuevo concepto, debemos señalar el proceso que transformó los otros tres en vértices de un triángulo cuya área puede ser pensada como dispositivación.

Superficie de registro: tomamos este concepto de El Antiedipo (Deleuze y Guattari, 2009). La superficie de registro del socius es el capital. Al convertirse todo flujo deseante sobre el socius en flujo capital, se produce en este cuerpo una superficie de registro y por lo tanto de control.

En una palabra, el socius como cuerpo lleno forma una superficie en la que se registra toda la producción que a su vez parece emanar de la superficie de registro. La sociedad construye su propio delirio al registrar el proceso de producción. (2009, p. 19)

El proceso de producción se registra al mismo tiempo que se produce, generando la sensación que el capital no es el fin del proceso sino su causa: si registramos sobre el 
capital, este se transforma en sostén del registro y en apariencia de la misma producción.

Todo parece (objetivamente) producido por el capital en tanto que cuasi-causa. Como dice Marx, al principio los capitalistas tienen necesariamente conciencia de la oposición entre el trabajo y el capital, y del uso del capital como medio para arrebatar el excedente de trabajo. Sin embargo, a la vez que se instaura rápidamente un mundo perverso embrujado, el capital desempeña el papel de superficie de registro en la que recae toda la producción. (2009, p. 19)

La superficie de registro permite llevar un control sobre las relaciones de producción asegurando así el cierre del ciclo productivo sobre el capital, y efectúa la inversión de estas relaciones universalizando y esencializando el papel del capital en toda producción.

Igual sucede con el Complejo de Edipo, producido como elemento genético en la formación deseante del sujeto, a través de la familia y de una producción deseante desplazada por la imagen de la represión del incesto (Deleuze y Guattari, 2009, p. 125). La familia da forma al deseo del niño, lo reconduce hacia formaciones establecidas y aptas para el socius, lo registra y controla; se hace casi-causa de la producción deseante del niño.

De igual modo comprendemos los distintos soportes de registro de la investigación académica. El diario de campo, las fotografías, videos, documentos, etc., como la escritura de la tesis; son superficies de registro. Conforman un conjunto que se articula en ella. Ésta es soporte de registro de la producción, le impone una forma determinada definida como académica. Generando la idea que es la única producción de conocimiento posible, ejerciendo un control sobre ella.

En nuestras investigaciones comprendimos que no es posible obviar ni negar estos modos que hacen a la propia academia. Los materiales con los que trabajamos se conciben como superficie de registro, aunque tomaban otro carácter: 
Como bloques de afectos y perceptos nos individuamos en diferentes configuraciones que conectan con otras intensidades que rodean y abordan estas configuraciones, insistiendo en los cambios, las transmutaciones que nos hacen a cada momento acontecimiento. El diario, deja de ser superficie de registro, memoria pura, para tornarse flujos intensos que presionan y componen nuevas materialidades. [...] Se compone de fotografías, emails, escritas afectivas apresuradas, ensayos cuidadosamente diseñados, grandes y pequeños esquemas, poemas y canciones. (Rey, 2015, p. 20)

Si nos restringimos a su uso objetivo y objetivante, no podemos rehuir de la superficie de registro y control que suponen. Pero acercándonos a sus aspectos intensos se vuelven elementos conectivos de la cartografía. Transformamos los objetos en fuerzas, la dimensión del control se diluye en la potencia colectiva de los elementos en juego:

El texto que sigue se construye a través de líneas que pretenden remarcar, acentuar, sobre todo indicar la existencia de algo que compone la situación presentada. Tal como si en una habitación uno nombrara las cosas: silla, puerta, escritorio, lápiz, libro. Indicar fuerzas, esa es la intención. (Granese, 2015, p. 190)

Superficie de registro, primer vértice. Presenta sus desplazamientos en el plano de inmanencia que delinea dispositivación como el espacio pasible de formateo y control, aunque aporta la materia esencial de la cartografía al penetrar en sus aspectos intensivos.

Agenciamiento: hay una comprensión que lograr sobre el relacionamiento de componentes heterogéneos cuyos efectos no podemos explicar solo por su cercanía. El movimiento que desborda la idea de puzle. No basta con combinar los elementos en juego. Hay algo más entre ellos. Quizás lo que denominamos como novedoso es lo que surge del agenciamiento y por eso su cercanía al acontecimiento. 
¿De qué depende que lo nuevo surja? ¿Nuevo para quién? El invento, lo nuevo, así como el acontecimiento, depende de las composiciones en juego. De los modos de encuentro entre las materias del espacio, las transformaciones de estos modos y la producción de nuevos modos (a los modos de encuentro les llamaremos semióticas. Comprendiendo la semiótica como un régimen de signo particular, que emerge en el entre de los encuentros, un agenciamiento). También depende de la capacidad de afectación a la que los agenciamientos preexistentes estén dispuestos. (Rey, 2015, p. 38)

El concepto surge de las producciones de Deleuze y Guattari. Lo presentan como el conjunto de relaciones entre elementos heterogéneos y asociado a una producción dividida en dos caras: agenciamiento maquínico deseante y agenciamiento colectivo de enunciación; o de otro modo, corporales e incorporales. Ésta distinción es posterior al mismo agenciamiento y no constituyente de él. "El agenciamiento no es agenciamiento de enunciación, no formaliza la expresión más que en una de sus caras; en la otra, inseparable de la primera, formaliza los contenidos, es agenciamiento maquínico o de cuerpos" (Deleuze y Guattari, 2006, p. 143).

Con esta distinción en corporales e incorporales, existen otras dos orientaciones del agenciamiento. Una cara vuelta hacia los estratos y otra al cuerpo sin órganos (CsO). Los estratos son el organismo, maniatan al hombre, pero también son imprescindibles para continuar la vida (2006, p. 165). Los autores definen el CsO como el deseo en su expresión pura y comprenden que conserva este estatuto aún en el deseo de aniquilamiento (2006, p. 169). El agenciamiento es el entre de estas caras: "Pues bien, a este respecto, el problema fundamental es invertir el agenciamiento más favorable: hacerlo pasar, de su cara orientada hacia los estratos, a la otra cara orientada hacia el plan de consistencia o el cuerpo sin órganos" (2006, p. 137).

No nos explayaremos en esto más de lo necesario para completar el segundo vértice. 
Estas dos caras permiten al agenciamiento transitar entre las intensidades puras del CsO, componiendo fuerzas a velocidades tendientes al infinito, integrando y transformando los componentes heterogéneos estratificados, con velocidades tendientes a cero. Entre ambas caras, el agenciamiento, cuyas dimensiones no se agotan en ellas, ya que al componerse en resonancia, se suponen potenciales no individuados.

Definimos así el segundo vértice como un movimiento descompuesto en dos dimensiones (maquínica y enunciativa) y en dos direcciones (estratos y cuerpo sin órganos); en una composición que es posible por efectos de resonancia.

Dispositivo: concepto de Foucault, aunque él nunca lo definió, lo hizo funcionar en sus investigaciones. Según Castro-Gómez, podemos entender dispositivo como un ensamblaje de prácticas discursivas y no discursivas:

Ahora bien, las prácticas (discursivas y no discursivas) son acontecimientos: emergen en un momento específico de la historia y quedan inscritas en un entramado de relaciones de poder. Sólo hay prácticas en red. Para Foucault no existen prácticas que sean independientes del conjunto de relaciones históricas en las cuales funcionan. Por eso, aunque las prácticas son singulares y múltiples, deben ser estudiadas como formando parte de un ensamblaje, de un dispositivo que las articula. (Castro-Gómez, 2010, p. 29)

Siguiendo este enunciado, podemos visibilizar los tres elementos genéticos de todo dispositivo descritos por Giorgio Agamben en ¿Qué es un dispositivo? (2011):

1) [El dispositivo] se trata de un conjunto heterogéneo que incluye virtualmente cada cosa, sea discursiva o no: discursos, instituciones, edificios, leyes, medidas policíacas, proposiciones filosóficas. El dispositivo, tomado en sí mismo, es la red que se tiende entre estos elementos. 2) El dispositivo siempre tiene una función estratégica concreta, que siempre está inscrita en una relación de poder. 3) Como tal, el dispositivo resulta del cruzamiento de 
relaciones de poder y de saber. (2011, p. 250)

El agenciamiento se encarna entre los estratos y el CsO, el sujeto entre el saber y el poder. En el cruce de sus líneas del agenciamiento y del sujeto surge el dispositivo como un modo de subjetivación.

El término dispositivo nombra aquello en lo que y por lo que se realiza una pura actividad de gobierno sin el medio fundado en el ser. Es por esto que los dispositivos deben siempre implicar un proceso de subjetivación, deben producir su sujeto. (Agamben, 2011, p. 256)

El dispositivo se hace al mismo tiempo que sus cuatro líneas de composición: líneas de visibilidad, líneas de enunciación, líneas de fuerza y líneas de subjetivación (Deleuze, 1999, pp. 155-156).

Todas las líneas son líneas de variación que no tienen ni siquiera coordenadas constantes. Lo uno, el todo, lo verdadero, el objeto, el sujeto, no son universales, sino que son procesos singulares de unificación, de totalización, de verificación, de objetivación, de subjetivación, procesos inmanentes a determinado dispositivo. Y cada dispositivo es también una multiplicidad en la que operan esos procesos en marcha, distintos de aquellos procesos que operan en otro dispositivo. (Deleuze, 1999, p. 158)

Cuando Deleuze dice en este sentido, es porque no se puede capturar a Foucault en un único sentido. Algunos autores no han tenido este cuidado al encerrar a Foucault aquello que les hace posible realizar ciertas afirmaciones, reduciendo el dispositivo a mecanismos técnicos, elementos de composición que aparecen como individualidades acabadas, materialidades detenidas, perdiendo la potencia creativa del dispositivo.

¿Qué es un dispositivo? En primer lugar, es una especie de ovillo o madeja, un conjunto multilineal. Está compuesto de líneas de diferente naturaleza y esas líneas del dispositivo no abarcan ni rodean sistemas cada uno de los cuales sería homogéneo por su cuenta (el objeto, el sujeto, el lenguaje), sino que 
siguen direcciones diferentes, forman procesos siempre en desequilibrio, y esas líneas tanto se acercan unas a otras como se alejan unas de otras. Cada línea está quebrada y sometida a variaciones de dirección (bifurcada, ahorquillada), sometida a derivaciones. (Deleuze, 1999, p. 155)

Tenemos nuestros tres conceptos articulados en función de la noción de dispositivación: movimiento que no restringe sus características a uno solo de los conceptos descritos. Dispositivación lo comprendemos como superficie de registro, también en sus aspectos más negativos: como el de un aparato de control, comprendiendo en este caso que tal superficie es la que aporta, también, la materia prima, la base de salto y operación transductiva que posibilita la producción de lo nuevo.

El mapa es la superposición de las superficies de registro, sumadas a un elemento orientador que articule estos diferentes planos, que no busque una unificación material, sino que mantenga la diversidad perceptiva de la experiencia. Los elementos orientadores de esta investigación, como ya dijimos, fueron los dinamismos espacio-temporales (quién, cuándo, dónde, cómo, cuánto), y todo lo que iba sucediendo que se acumulaba en forma de imágenes-recuerdo e iban produciendo cada vez otras dispositivaciones a través del reconocimiento atento. (Rey, 2015, pp. 103-104)

Es también agenciamiento, realizando una composición de elementos heterogéneos en dos sentidos simultáneos, que permiten distintas operaciones entre los estratos y el $\mathrm{CsO}$, aportando fluidez en los primeros, densificando y extrayendo materialidades en el segundo.

Se produce una trama significacional que no es una racionalización, sino un modo de funcionamiento. Esta trama significacional es indisociable a un funcionamiento: es lo que comprendemos por dispositivo, como líneas de enunciación, de fuerza y de subjetivación. 
Probablemente la característica más relevante de dispositivación resida en la orientación del concepto. Dispositivación se presenta como acción dirigida hacia el dispositivo. Como si dispositivo fuera un centro en torno al cual gira dispositivación. Por otro lado, más allá de este aspecto casi de estratificación, señalemos la otra parte del concepto. Su naturaleza dinámica, al presentarse como una acción en acción. No es posible un estado de dispositivación. Siempre un movimiento y más, un movimiento accionando sobre algo: una fuerza. Podemos pensar dispositivación como una fuerza. (Rey, 2015, p. 43)

La cartografía como método es una máquina compleja compuesta por infinidad de dispositivaciones: movimiento, funcionamiento, entramado significacional de intensidades que delinean un espacio-tiempo; unas dentro de otras, sobre otras, encadenadas, superpuestas. Dispositivaciones que surgen, funcionan, producen nuevos modos, significan y se disuelven, dejando un rastro que resultará base para próximas dispositivaciones.

En la tesis El acontecimiento en las prácticas psicológicas podemos pensar la producción del concepto desonancia como una dispositivación, que produce y da cuenta de una trama significacional y un funcionamiento, del tipo que estamos describiendo:

Después de eso que se pasa, las cosas se siguen pasando. Ya estando en otros lugares, en otros espacios. El ciclo comienza y recomienza, y aquellas desonancias se recuperan como resonancias. Resonancias de los efectos de las desonancias. En los Espacios de Intensificación del Plano de Inmanencia, "soy Mara entera, o casi, en ese espacio y lo que se mueve en ese espacio se queda moviendo en todos mis ámbitos" (Participante PAIE, 2014). [...] "No tuve que pensar, mi cuerpo ahora dolorido solo recordó las sensaciones, los olores, las caricias, los fluidos, las respiraciones, los tiempos, la temperatura, los lugares en el espacio y como se habitaron" (Participante Esp. Desnudo, 2014). 
La significación no tiene que ver con una racionalización, el cuerpo trajo los recuerdos que compusieron con el presente doloroso. No es necesario pensar racionalmente, hay un pensamiento corporal en resonancia de la desonancia que habita la memoria. (Rey, 2015, p. 139)

En esta investigación se crearon algunos espacios como dispositivaciones. Los llamamos Espacios de Intensificación del Plano de Inmanencia: dirigido a intensificar afectaciones de un grupo de investigación sobre violencia de género en el ámbito educativo.

El Espacio de Intensificación del Plano de Inmanencia fue regulado por la misma dinámica de los equipos de trabajo. Con esto se buscó abrir espacios lisos, entre los institucionales, donde se intensificó la acción inmanente al encuentro, como un espacio privilegiado de posibilidad de dispositivación de acontecimientos. [...] Esta actividad se acerca más a un movimiento de dispositivación que a un dispositivo constituido. Se constituyeron como puntos catástrofes dentro de los procesos institucionales en que se incluía el trabajo de campo. Y maravillosamente, estos puntos catastróficos, dejaban una marca en los cuerpos que posteriormente continuaban el proceso de trabajo que veníamos llevando. (Rey, 2015, pp. 102-103)

Como se aprecia, aparece la huella de una dispositivación diluida que pasa a los espacios de trabajo institucional. También notamos que dentro de esta dispositivación, estos espacios-movimiento, se producen otras dispositivaciones que dejan también sus micro-huellas en los participantes, aportando a la producción de nuevas subjetividades:

"Corporeando... en el piso de madera lisa que se perdía en el movimiento ya no marcaba un abajo, tampoco un límite. Ese fue un encuentro de intenciones desconocidas iniciales que se volvió una trama de significaciones que conectaban por algún lado" (Participante PAIE, 2014). [...] Corporeando es un 
movimiento que pierde la percepción de la madera que hace piso. "El suelo sirve para sostener a los hombres" (Uexküll, 2014, p. 84). Solo que en el corporear, la madera ya no es piso, dado que su utilidad se pierde y no sostiene nada, por lo que pierde significado y por lo tanto deja de ser un objeto para quien corporea. Sin embargo, no es que no haya trama de significaciones, de relaciones, de razones (como lo entiende Deleuze de Spinoza). Se produce una nueva trama de significaciones, el umwelt se produce a partir de otros puntos de significación. "Se volvió una trama de significaciones que conectaban por algún lado". (Rey, 2015, p. 138)

Dispositivación es un concepto anudado a la producción de conocimiento cartográfico. Permite esta producción como acontecimiento, al comprender un registro productivo entre velocidades infinitas y la casi detención, agenciando elementos heterogéneos de modo inédito. La dispositivación aparece como un elemento genético del método cartográfico, indisociable del mismo. La dispositivación como productora de los campos de investigación, y estos siendo los campos de fuerza que la misma dispositivación debe seguir.

\section{El campo de fuerzas que fuerza a pensar}

Cuestionamos la noción de campo. En Ciencias Sociales hablamos de campo y de trabajo de campo. Distinguiendo un espacio, fundamentalmente, a partir de la población investigada. El campo puede coincidir con un territorio geográfico, es el caso, en términos generales, de la etnografía. Otras veces esta coincidencia no es tan específica y amplía su territorio: ciudad, país, región. Lo que nuclea ambas situaciones es la población objetivo. Y el trabajo de campo remite a las actividades realizadas con la misma en el marco de la investigación.

Se distingue, luego, trabajo de campo de mesa de trabajo: lugar donde el investigador articula reflexivamente los materiales brindados por el campo (Álvarez Pedrosian, 
2011). Si decimos que cartografiar es estudiar el acontecimiento, el cual es más que las formas y representaciones que cobra; entonces ya no estamos seguros ni de cuál es el campo en tanto territorio ni población, ni dónde está el trabajo de campo ni la mesa de trabajo.

Decimos, también, que el trabajo cartográfico sigue una deriva producida por una afectación, es decir que tal afectación es el borde del que hablamos más arriba. Es el pliegue de acontecimiento y cartógrafo. Ya no se puede detener el movimiento de trazado que lleva a uno a través del otro. Es un umbral de sensibilidad: o se lo deja o se lo sigue.

Es complejo hablar de este momento donde cae la posibilidad de representar porque algo ha hecho borde, siendo su condición de borde lo que lo define, tornándose inaprensible. Ya no se puede definir con certeza, como a priori de un trabajo cartográfico, dónde empieza y termina el campo, quién es y quién no es población objetivo de la investigación.

Estoy rodeado de papeles, de mails impresos con vivencias y reflexiones propias y de las personas con las que trabajé durante la investigación. Este mismo cuarto está empapelado de esquemas producto del encuentro con los escritos de los pensadores que componen también esta tesis. Yo mismo estoy lleno de recuerdos y momentos particulares de los encuentros en el campo extenso de investigación. ¿Y dónde está el campo en última instancia? Siempre en última instancia es un agenciamiento que se produce en esta conjunción donde el pegamento que une todas estas materialidades heterogéneas es la afectación, la violencia de ellas sobre el pensamiento y que lo obliga a producir. (Rey, 2015, p. 112)

En este momento una fuerza nos fuerza a pensar. Deleuze:

Lo primero en el pensamiento es la fractura, la violencia, el enemigo; y nada supone la filosofía, todo parte de una misosofía. No se debe contar con el 
pensamiento para sentar la necesidad relativa de lo que piensa, sino por el contrario con la contingencia de un encuentro con lo que fuerza a pensar, para levantar y erigir la necesidad absoluta de un acto de pensar, de una pasión de pensar. Las condiciones de una verdadera crítica y de una verdadera creación son las mismas: destrucción de la imagen de un pensamiento que se presupone a sí mismo, génesis del acto de pensar en el pensamiento mismo. (Deleuze, 2009b, p. 215)

¿Qué es esta fuerza que fuerza a pensar? Tomamos la etnografía como una metodología paradigmática en la identificación de campo con territorio geográfico, la delimitación de su noción de trabajo de campo definiéndolo de modo preciso, como así también lo hace con la población. Etnografía y cartografía tienen puntos en común. No obstante, se distancian en algo fundamental: la cartografía no puede definir estos elementos de modo estable pues, cuál es el territorio de una fuerza, cuál es el sujeto de una fuerza.

La cartografía es la pregunta por lo otro. Obsérvese que no decimos "el" otro (tal vez ésta sea la pregunta etnográfica). Decimos "lo" otro, marcando lo impersonal de la fuerza, del acontecimiento, pues ésta atraviesa cuerpos, cosas, territorios y es, en sus cristalizaciones donde se produce lo personal, pero no se confunde con esos puntos de estabilización. La fuerza es un afuera. Desde hace ya mucho, no se precisa ir a otra cultura a investigar la diferencia. Hoy la pregunta por el otro (en etnografía), por lo otro (cartográficamente), se realiza en la misma cultura, ciudad e instituciones del investigador.

Lo otro remite al borde. Es, también, el afuera en el investigador. Llegar al afuera en uno mismo. Nos extrañamos de lo otro, no lo circunscribimos a nuestras referencias, no reconocemos. Lo otro deviene otro no como eso que no somos nosotros, sino otro en tanto presencia de una diferencia radical en nosotros mismos. Uno deviene otro para sí. Blanchot cita a René Char: “CCómo vivir sin desconocido ante sí?” (2008, p. 
379). Recién en este sentimiento de extrañeza comienza el esfuerzo del pensamiento.

Por esto, porque es otro en uno, es que ya no podemos detenernos. Hay que seguir la línea de fuerza. Hacia dónde, hasta cuándo y cómo, solo el camino cartográfico podrá decirlo. Podemos asegurar una cosa: todo tendrá que ver con ese borde, y esto hará única a la investigación. Toda la investigación será el despliegue del cartógrafo y tendrá que ver con sus potencias y con la pasión de su pensamiento.

Deleuze ofrece algo importante, dice: "una pasión de pensar". Pasión refiere a su etimología pathos, estar afectado de necesidad, deseo y potencia de pensar. En tanto afecto, es difícil presuponer un método sistemático que dé cuenta del camino del pensamiento.

En la investigación sobre La invención en la práctica del Maestro Comunitario, quedamos atrapados en la pregunta por lo comunitario sin poder pensarla. Ejemplificamos con un extracto del proceso del investigador:

En esos dos Diarios de Campo, se aprecia el proceso de la investigación, que no es otro que mi propio proceso como investigador. En un primer momento el Diario está construido en base a la descripción de situaciones. También se encuentran muchas citas de la bibliografía que leía en ese momento. Al finalizar el primer semestre (mitad del trabajo de campo), comienzan a aparecer extensas reflexiones sobre lo que voy viviendo. Hay un pasaje de un abordaje teórico a otro más problemático de la vivencia. Esto es espejo de lo que viví como investigador. [...] de a poco mi interés cambió, cada vez fui sintiéndome más parte de la vida escolar, de la problemática escolar. [...] Las lecturas bibliográficas se fueron reduciendo: solo acontecían en el ómnibus (316 Camino Maldonado) yendo de mi casa a la escuela. Todo empezó a circular en torno a lo que estábamos viviendo con las MC. (Granese, 2015, p. 103)

¿Qué implica el término "lo comunitario"? ¿Cómo es habitar ese acontecimiento? 
¿Qué es esto de lo que no se puede dar cuenta? La pregunta por "lo comunitario" resultaba impensable, desesperante, por tanto, apasionante.

La intuición condujo hacia un cuento de Julio Cortázar. Creímos que en sus libros, artísticamente, podría haber una respuesta. Se revisaron los índices, buscando un cuento que hablara de una escuela. Allí estaba La escuela de noche, del libro Deshoras del año 1982.

Remitimos a la tesis para un breve análisis del cuento (Granese, 2015, pp. 166-167). Aquí queremos mostrar que la investigación no es representación de algo externo al investigador. También que, en tanto rizoma, implica la articulación de diversas materias (políticas educativas, diagramas territoriales, literatura, etc.). Finalmente, que el campo no puede reducirse a un espacio geográfico ni una población específica: la fuerza que se sigue está en Punta de Rieles (en el caso de esta investigación), en un cuento, en el investigador.

Cuando se siguen fuerzas el campo se vuelve tan amplio y diverso, lejano e íntimo, como lo produzca el propio trazado del mapa. Ese mapa no es más que el despliegue del pliegue del cartógrafo en el acontecimiento. El despliegue de la implicación del cartógrafo:

El análisis de la implicación no es ni más ni menos que el intento por desplegar la mayor cantidad de líneas que envuelven (implicare) a quien investiga. Es erróneo pensar en altos o bajos grados de implicación. Como es redundante realizar un apartado que hable de la implicación, pues toda la investigación no es más que el despliegue de esa implicación. Lo que se hace, la palabra utilizada, el texto leído, la institución que financia, la idea que da fuerza, aquello que se siente. [...] Todos son envolturas del autor. La implicación es toda la investigación. (Granese, 2015, p. 95)

El acontecimiento es imposible delimitarlo en un campo. El borde siempre desborda: Y cuando este investigador, en su propuesta, ingresa al campo, lo vive, lo 
integra, lo produce; ese campo se hace vida, vida del investigador. El campo de investigación, es el campo de la vida. [...] no se trata únicamente de decir que la investigación se termina llevando a la vida entera, sino que aunque logremos restringir la investigación a los campos de trabajo propuestos, estos campos de trabajo terminan siendo la vida del investigador, porque toda su afectación se juega en ese espacio, así como en los otros por los que transcurre su día a día. (Rey, 2015, p. 105)

Finalmente el campo es creación. La cartografía, para seguir una fuerza debe inventar los modos de intensificarla. Podríamos usar la metáfora óptica: visualizar, sacar a luz. Pero sigue refiriendo a lo perceptual, a la distancia. La cartografía precisa metáforas de ruptura y discontinuidad. Algo insiste, y lo hace justamente porque adquirimos una sensibilidad particular al acontecimiento, es necesario crear el dispositivo y las técnicas que produzcan el campo por el cual se pueda trabajar con eso que insiste.

En la tesis La invención en la práctica de los Maestros Comunitarios, se creó un "taller de escritura" con nueve MC, coordinado por el investigador (Granese, 2015, pp. 111114). El motivo era escribir sobre aquello no dicho de la labor, a pesar de todo lo que sí se dice. El trabajo implicó dos meses de reuniones semanales para mapear ideas que luego se trabajaban en un documento on-line. Se produjo un artículo llamado "Lo no dicho de lo dicho" publicado en la revista Hacer escuela entre todos de ANEP (Granese et al., 2013). Este taller fue el espacio donde comenzamos a trabajar el acontecimiento de "lo comunitario".

La tesis El acontecimiento en las prácticas psicológicas muestra esta característica inventiva en varias actividades. “¿Cómo investigar el acontecimiento?” es la pregunta que recorre todo el trabajo. $Y$ esta pregunta (y su respuesta) es inmanente. La propia búsqueda plantea la pregunta al tiempo que la responde. Porque el acontecimiento está siempre aconteciendo y por eso mismo es tan difícil delimitarlo (necesidad intrínseca de cualquier investigación). 
El acontecimiento está aconteciendo. ¿Con qué medios trabajarlo? La tesis abre varios espacios: Espacio de intensificación del plano de inmanencia con las estudiantes del PAIE; Espacio experimental del desnudo; el espacio clínico particular (Rey, 2015, pp. 110-126).

¿Cómo investigar el acontecimiento? No pretendemos fórmulas metodológicas, a no ser ésta: llevar esta pregunta por espacios que intensifiquen la amplitud del acontecimiento. Eso es cartografiar. El último campo a crear es la escritura, sea una tesis, un artículo, etc.

El último campo de investigación es éste: la escritura. Es un encuentro de materias diferentes, que afectan de manera diferente y que se conjugan en este espacio y momento para producir un agenciamiento maquínico y enunciativo, en fin, agenciamiento. $Y$ que este agenciamiento se produce básicamente a través de la afectación de quién escribe, este Yo que de alguna manera también es un agenciamiento de todas esas instancias, de todos esos encuentros, afectado en su momento por ellos. En definitiva, y más que Yo, Singularidad. (Rey, 2015, p. 113)

La escritura no es el traslado de lo que pasó en un espacio-tiempo determinado a un medio de registro. La escritura no representa un campo independiente de ella. La escritura es creación de ese campo y es campo ella misma. En sus trazos se dibuja el mapa cartográfico. Tomemos de ejemplo la escritura de este artículo: creamos un vínculo entre los conceptos de cartografía, dispositivación y acontecimiento. Creamos una relación de necesidad entre ellos que no antecede a esta escritura. No se encuentra en nuestras tesis.

El artículo no las representa. Hay elementos que en ellas son "secundarios" y aquí cobran relevancia, no porque planificamos hablar de ellos, sino porque la escritura del artículo trazó un mapa nuevo con aquellos otros mapas que son las tesis y, esto, solo porque escribiendo comprendimos nuevas facetas de los conceptos, encontrando 
nuevas tesis.

A su vez, en esta escritura aparecen otros conceptos mostrando su potencia. Han hecho máquina con nuestro ejercicio de pensamiento. Pero apenas son incipientes. Solo nuevas experiencias dirán si se asientan con plenitud de inteligibilidad o desaparecen. Son los conceptos de borde, afuera, desonancia. Aún no podemos decir qué pasará con ellos.

\section{Conclusión}

Son varios los motivos que nos llevan a pensar en la cartografía como un método de investigación válido y necesario para la psicología. Necesario porque la psicología oscila entre la práctica científica y la práctica clínica. Cuando se impone la necesidad de producir conocimiento académico en psicología, la práctica científica ocupa toda la escena, reduciendo la clínica a los elementos que la ciencia imperante puede concebir e incluir en sus métodos de investigación, invisibilizando, cuestiones tales como los acontecimientos, las intuiciones, los devenires, que hacen a la clínica tanto como los estados, los procesos continuos, los datos comportamentales, los resultados psicométricos, etc.

Válido para un campo epistémico no representativo; donde el investigador no quede excluido de lo investigado; donde las descripciones produzcan el conocimiento; donde se expresen, a través de la escritura y otros registros, los acontecimientos de la misma investigación, y no que la escritura represente una serie de estados o un movimiento del campo.

Epistémicamente la investigación en psicología se interroga acerca de la producción de conocimientos sobre campos de problemas procesuales, en movimiento y singulares. ¿Cómo se produce conocimiento sobre un acontecimiento? Éste no puede ser representado, pues es aquello que se produce entre dos estados, es la vivencia del movimiento. "Cuando tomo cortes inmóviles sobre los movimientos, es siempre 
para reconducirlos a una homogeneidad uniforme de tiempo abstracto gracias a la cual, precisamente, uniformizo todos los movimientos y ya no comprendo nada del movimiento mismo" (Deleuze, 2009a, p. 25). Esto no puede trabajarse sin una vivencia del acontecimiento y no su simple observación.

La descripción clásica de una observación busca representar lo observado, pero de alguna manera lo produce. Así esta pseudo-representación no es más que la producción de un nuevo movimiento distinto del original, ya que no hay manera de representar un movimiento. Solo vivenciarlo a la vez que es producido por esa vivencia en la que estamos insertos.

Esta representación de estados produce un tipo de conocimiento: el conocimiento científico clásico representativo, que busca fundamentar una verdad trascendente a cualquier encuentro, tal como lo enuncia Deleuze en el octavo postulado de la imagen representativa del pensamiento:

Hay en este principio una subordinación del aprendizaje al saber. Uno aprende solo para saber, el aprender es un intermediario necesario, pero en esta imagen debe ser trascendido por el saber. Entonces lo que cobra importancia aquí es el método racional como la única forma válida de alcanzar este saber. (Deleuze, 2009b, p. 251)

Si buscamos producir conocimiento sobre la práctica psicológica, debemos tener claro que hablamos de un conocimiento procesual, no exclusivamente acumulativo. En este tipo de investigación, sujeto y objeto hacen borde en el encuentro, por tanto no hay manera de conservar una posición de exterioridad respecto a lo investigado. Lejos de ser un obstáculo, este hacer borde es la condición necesaria para acceder a los acontecimientos.

En este trabajo buscamos presentar algunos conocimientos sobre la cartografía a partir de nuestras investigaciones de Maestría. Los pensamos como un aporte a las profusas producciones sobre el tema. La selección realizada sobre estos conceptos, 
nos llevó a producir a través de la misma escritura, generando de esta manera una línea de sentido que no existía anteriormente. Así, hasta este mismo artículo se vuelve un efecto de aquellas investigaciones del 2015, produciendo nuevos conocimientos. Esta línea de sentido la podemos describir de la siguiente manera y responde a los aportes metodológicos aquí presentados:

Siendo el acontecimiento -con sus características de heterogeneidad, discontinuidad y producción inmanente del campo- constituyente de toda práctica psicológica a ser investigada, la cartografía se presenta como un método pertinente. Las dispositivaciones son movimientos de semi-estructuración inmanentes a los espacios y las acciones, mediadores válidos entre los aconteceres caóticos, rizomáticos y la producción de conocimiento resultante del seguimiento de las líneas de fuerza. Las dispositivaciones delinean los campos de trabajo de la investigación, configurados por estas líneas de fuerza o de potencia, actualizaciones de otros campos preestablecidos que se transforman en la inmanencia del acontecimiento.

Finalmente la cartografía, más allá de todo lo escrito, no deja de ser un modo. Un modo de percibir, accionar y afectarse. Un modo de recorrer líneas de fuerza, donde la fuerza también es constituida por la cartografía. Los campos de fuerza no nos preexisten. Seguramente hubieran otros antes de nosotros, pero nunca podremos dar cuenta de ellos. Quizás la afirmación más importante en la que se basa la disposición cartográfica es la imposibilidad de dar cuenta de algo sin producirlo al mismo tiempo. Eso nos pone en un lugar complejo ante la pregunta de para qué investigamos. Ya no es confirmar una hipótesis, pues no la hay cuando ingresamos de cuerpo entero a un determinado campo de trabajo y como componentes productores del campo. La investigación ya no se hace sobre algo en particular, más que sobre nosotros mismos en tanto borde.

Ese nosotros es un nosotros no individualizante. No se termina el nosotros en el nosotros físico que nos conforma. En este sentido toda enunciación es colectiva y 
distributiva, y solo es posible porque el plano de consistencia está preparado para que pueda ser dicha, aun en la resistencia a este decir.

Comenzamos centrados en determinadas preguntas, nos enfocamos en determinados campos, pensamos en determinadas actividades, nos hacemos un cronograma. $\mathrm{Y}$ cuando entramos en la investigación, en los campos propuestos, en las lecturas, en las vivencias, todo lo anterior funciona como una brújula desimantada, que más o menos nos orienta en alguna dirección, y solo con bastante esfuerzo logramos recordar eso que era algo así como nuestro norte, mientras la aguja sigue perdiendo su fuerza magnética, hasta que ya no importa, pues lo que estamos descubriendo, sintiendo, viviendo y pensando es lo más importante de nuestra vida y tiene que ser dicho. Sin importar de manera primordial ni fundamental cuáles eran los objetivos de esta investigación. Al final, la cartografía era el modo de seguir las líneas de un rizoma y nunca sabemos hacia dónde nos llevan estas líneas. (Rey, 2015, p. 106)

\section{Referencias}

Agamben, G. (2011). ¿Qué es un dispositivo? Sociológica (México), 26(73), 249-264.

Álvarez Pedrosian, E. (2011). Etnografías de la subjetividad: herramientas para la investigación. Montevideo: Licenciatura en Ciencias de la Comunicación de la Universidad de la República.

Blanchot, M. (2008). La Conversación infinita. Madrid: Arena Libros.

Castro-Gómez, S. (2010). Historia de la gubernamentalidad razón de Estado, liberalismo y neoliberalismo en Michel Foucault. Bogotá: Siglo del Hombre. Recuperado de http://site.ebrary.com/id/10637260

Deleuze, G. (1989). El Pliegue: Leibniz y el Barroco. Editorial Paidós.

Deleuze, G. (1999). ¿Qué es un dispositivo? En Michel Foucault, filósofo. Barcelona: 
Gedisa.

Deleuze, G. (2002). Lógica del sentido. Madrid: Editora Nacional.

Deleuze, G. (2009a). Cine 1 : Bergson y las imágenes. Buenos Aires: Cactus.

Deleuze, G. (2009b). Diferencia y repetición. Buenos Aires, Argentina.: Amorrortu.

Deleuze, G. (2015). La subjetivación: curso sobre Foucault. Buenos Aires: Editorial Cactus.

Deleuze, G. y Guattari, F. (2006). Mil mesetas: capitalismo y esquizofrenia. Valencia: Pre-Textos.

Deleuze, G. y Guattari, F. (2009). El anti-edipo: capitalismo y esquizofrenia. Barcelona: Paidós.

Foucault, M. (2006). Seguridad, territorio, población: curso en el Collège de France (1977-1978). Buenos Aires: Fondo de Cultura Económica.

Foucault, M. (2007). Nacimiento de la biopolítica: curso en el Collége de France (1978-1979). Buenos Aires: Fondo de Cultura Económica.

Granese, A. (2015). La invención en la práctica del Maestro Comunitario (Tesis de maestría en Psicología Social). Universidad de la República, Facultad de Psicología.

Granese, A. (2016). Lo comunitario: controversias del término en boca de sus actores. Psicología, Conocimiento y Sociedad, 6(1), 63-89.

Granese, A., Fernandez, A., Luzardo, R., Mazzini, M., Menesses, P., Quartino, Y., ... Silva, J. (2013). Lo no dicho de lo dicho. Hacer escuela entre todos, 3(3), 5768.

Guattari, F. (1989). Cartografías esquizoanalíticas. Buenos Aires: Manantial.

Guattari, F. (1992). Caosmosis. Buenos Aires: Manantial.

Guattari, F. (2013). Líneas de fuga por otro mundo de posibles. Buenos Aires: Cactus.

Passos, E., Kastrup, V. y da Escóssia, L. (2009). Pistas do método da cartografia. Porto Alegre: Sulina. 
Perlongher, N. (1996). Los devenires minoritarios. En Prosa Plebeya. Ensayos 1980 1992. Buenos Aires: Colihue.

Rey, J. (2015). El acontecimiento en las prácticas psicológicas (Tesis de maestría en Psicología Social). Universidad de la República, Montevideo, Uruguay. Recuperado de https://www.colibri.udelar.edu.uy/jspui/bitstream/123456789/4895/1/Rey\%2c\%2 OJavier.pdf

Rolnik, S. (2006). Cartografia sentimental: transformações contemporâneas do desejo. Porto Alegre: Sulina.

\section{Formato de citación}

Rey, J., Granese, A. (2018). La cartografía como método de investigación en psicología. Psicología, Conocimiento y Sociedad, PREPRINT, 1-34. doi: http://dx.doi.org/10.26864/PCS.v9.n1.4 